\title{
JOURNAL.RU
}

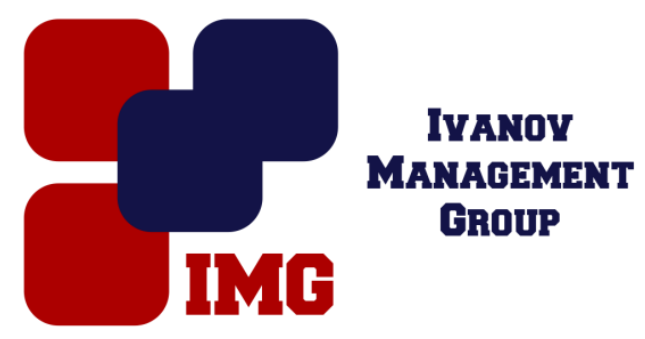

Дергунов С.А., Кулешов И.В., Кутлюк А.Б.

Оренбургский государственный университет Оренбург, Россия

doi: 10.18411/lj-30-06-2017-51

idsp 000001:1j-30-06-2017-51

\section{Создание логистических систем в дорожном строительстве}

\section{Аннотация}

В статье рассматриваются основы принципы строительства автомагистралей, на основе логистического подхода и ее практического применения.

Ключевые слова: логистика, дорожное строительство, эффективность, логистический бизнес-процесс.

В настоящее время дорожная сеть общего пользования Российской Федерации по своим количественным и качественным характеристикам далеко не в полной мере отвечает требованиям автомобильного транспорта. Около половины федеральных дорог требуют ремонта, более $40 \%$ нуждаются в усилении дорожной одежды, около $20 \%$ - в улучшении состояния покрытия. Состояние почти $40 \%$ федеральных дорог оценивается как неудовлетворительное. Технический уровень состояния местных дорог также чрезвычайно низок. По оценкам специалистов, для удовлетворения потребностей экономики в автомобильных перевозках протяженность автодорог общего пользования следует увеличить, по крайней мере, в 2,5 раза, в основном за счет развития местной дорожной сети. Сложившийся за годы реформ механизм принятия инвестиционных решений в отрасли несовершенен. В последнее время как заказчик, так и непосредственные исполнители работ - подрядчики, фактически отказались от планирования дорожных работ. Это приводит 
к нерациональному выбору

объектов

строительства

и неэффективному использованию ресурсов. Для совершенствования методов принятия инвестиционных решений в дорожном строительстве требуется поиск новых подходов к планированию и организации много проектной деятельности дорожно-строительных фирм. С учетом отраслевых особенностей дорожного строительства наиболее эффективным может стать логистический подход.

В современной практике дорожного строительства управление материальными ресурсами зачастую осуществляется на основании общеупотребимых, но далеко не всегда эффективных и прогрессивных методов управления транспортными, погрузо-разгрузочными и другими операциями, являющимися неотъемлемой частью материального обеспечения технологических процессов строительства. Бизнес-процессы снабжения в сфере производства работ в таком случае формируются исключительно под воздействием производственных требований и не учитывают принципы экономической эффективности. Как следствие такого отношения к системе управления ресурсами, в деятельности дорожно-строительной организации на каждом этапе процесса материального снабжения возникают дополнительные затраты, которых можно было бы избежать. С учетом того, что строительство автомобильной дороги занимает длительный период времени, в течение которого осуществляется значительное количество бизнес-процессов, связанных с материальным снабжением (от выбора поставщика до операций с материалами на участке производства работ), даже незначительные дополнительные затраты каждого бизнес-процесса по объекту выливаются в существенные потери денежных средств. Такого рода неосмотрительность может оказать в будущем существенное влияние на финансовое состояние организации и её конкурентоспособность.

В настоящее время решение проблем разработки новых форм организации строительства объектов на основе современных методов управления становится важной и актуальной задачей. Организация процесса снабжения объектов дорожного строительства необходимыми материальными ресурсами заключается в формировании рациональной системы взаимозависимых элементов, каждый из которых должен максимальным образом обеспечивать не только возможность бесперебойного осуществления технологических процессов строительства, но и максимальное удобство применения. При этом элементы должны функционировать эффективно не только по отдельности, но и вместе, формируя сложную взаимосвязанную структуру, оказывающую, в конечном 
счете, влияние не только на деятельность ответственных подразделений, но и на всю организацию в целом.

Повышение эффективности деятельности организации может достигаться за счет формирования в дорожных организациях логистической системы. Такая система должна обеспечивать необходимый уровень гибкости и адаптивности, так как внешняя среда дорожной организации динамична и оказывает существенное влияние на показатели её деятельности. Логистическая система также должна быть способна подстраиваться под изменяющиеся требования внутренней среды, полностью удовлетворяя требованиям всех производственных подразделений. С другой стороны, логистическая система должна быть достаточно устойчивой, чтобы не подвергаться деструктивному влиянию множества факторов, оказывающих воздействие на процессы материально-технического снабжения в отрасли.

Для формирования логистической системы, удовлетворяющей этим требованиям необходимо провести логистический анализ сферы строительства. Можно выделить следующие задачи логистического анализа сферы строительства:

- выявление логистических резервов, включая резервы оптимизации экономических потоков, резервы сопряжения технологий резервы управления запасами;

- оценка логистического потенциала каждого участника процесса строительства;

- установление возможности сопряжения экономических интересов участников логистических цепей и систем;

- выработка прикладных организационно-технических и социальноэкономических мероприятий по логистизации сферы строительства.

Одним из ключевых элементов такого подхода является оптимизация логистических бизнес-процессов. Логистический бизнес-процесс в дорожном строительстве - это упорядоченная последовательность действий, в результате которой посредством управляющего воздействия осуществляется преобразование входных ресурсов процесса в результат, определяемый логистическими целями.

Ключевым свойством логистического бизнес-процесса является то, что это логически взаимосвязанная совокупность действий, определяемая отношениями, возможностями, ограничениями и ресурсами внутри конечного множества субъектов и объектов, объединяющихся в систему с целью получения 
конкретного результата, отчуждаемого или потребляемого самой системой. Внутри логистических бизнес-процессов выделяются подпроцессы, которые, в свою очередь состоят из подпроцессов меньшего порядка и так до уровня, на котором дальнейшая детализация процессов не будет иметь смысла. В рамках одного объекта совокупность этих процессов образует единый укрупненный логистический бизнес-процесс.

Однако строительство одновременно нескольких объектов силами одной строительной организации требует координации и взаимоувязки нескольких объектных систем. В этом случае формируется строительный поток, в основе которого лежит совокупность нескольких объектных потоков, образующих межобъектный процесс. Преобладающие в нем связи, естественно, ресурсные, обусловленные необходимостью рационального распределения ресурсов (как материальных, так и энергетических, и трудовых) между различными объектами в соответствующие периоды времени. Такое усложнение делает необходимым контроль за оптимизацией и рационализацией не только бизнес-процесса в рамках конкретного объекта, но и в их совокупности и взаимосвязи в каждый отдельный момент времени.

Дорожное строительство является одной из отраслей, обладающих наиболее ярко выраженными особенностями, оказывающими влияние на все процессы организации и управления. Отраслевые особенности дорожного строительства, связанные, прежде всего, с технологической спецификой производства работ, предъявляют ряд требований к организации логистических бизнес-процессов на предприятиях, делающих их узкоспециализированными и направленными на удовлетворение логистических потребностей конкретной отрасли.

Если объектом изучения принимать все сферы деятельности дорожной организации, бизнес-процессы в ней в зависимости от характера деятельности и отношению к строящемуся объекту делятся на основные (операционные), управляющие и вспомогательные. Операционные бизнес-процессы являются фундаментом основной деятельности, остальные бизнес-процессы либо оказывают управленческие воздействие на основные, либо служат для их поддержания и обслуживания. Применительно к логистическим же процессам, мнения ученых разделились. Так, одни относят всю совокупность логистических бизнес-процессов к основным, другие ученые к основным бизнес-процессам относят только процессы внутрипроизводственной логистики, а бизнеспроцессы заготовительной, информационной и прочих видов логистики - к 
вспомогательным. Так или иначе, одной из основных задач логистизации дорожного строительства является их оптимизация.

Оптимизация логистических бизнес-процессов в традиционном понимании призвана решить ряд задач. Во-первых, это сокращение времени осуществления операции в согласовании с темпом продвижения потока строительства и с учетом тех случаев, когда сокращение времени невозможно или нерационально и может повлиять на технологические характеристики строящегося объекта (к особым случаям относят, прежде всего, операции с горячими асфальтобетонными смесями). Во-вторых, это минимизация затрат, связанных как с оперативными манипуляциями с материальными ресурсами на всем пути перемещения материального потока (межобъектного или в рамках одного объекта), так и с управлением этими процессами. Причем такая экономия включает в себя не только затраты на закупку, транспортировку, складирование, погрузо-разгрузочные работы, но и экономию трудовых ресурсов и производственных мощностей непосредственно на месте производства работ.

Поэтому прежде чем формировать логистическую систему, необходимо определить критерий, учитывающий комплексный характер требований.

В настоящий момент для внедрения в практику деятельности дорожных предприятий инструментария логистики и построения логистических систем необходимо устранить различного рода барьеры, мешающие логистизации дорожно-строительной отрасли.

\section{$* * *$}

1. Логистика в России: новые пути раскрытия потенциала. М.Волков.

2. Экономика дорожного строительства: учеб. Пос.: в 2 ч. Ч. 2. Гавриш В.В.

3. Экономическое обоснование программы развития сети автомобильных дорог. // Экономика строительства, №3, 1999 г. С.28-33. Беляков Г.С.

4. Экономико - математические методы в строительстве. Методические указания. Изд. Мордовский ун-т Саранск 2006. 36с.

5. Развитие логистики в строительстве: особенности, перспективы, методы принятия решений. Плетнева Н.Г., Власова Н.В. 